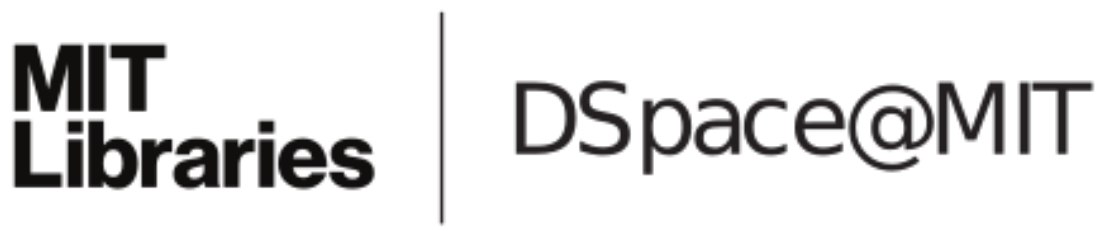

\author{
MIT Open Access Articles
}

Deriving soil moisture with the combined Lband radar and radiometer measurements

The MIT Faculty has made this article openly available. Please share how this access benefits you. Your story matters.

Citation: Jiancheng Shi et al. "Deriving soil moisture with the combined L-band radar and radiometer measurements." Geoscience and Remote Sensing Symposium (IGARSS), 2010 IEEE International. 2010. 812-815. (c) 2011 IEEE.

As Published: http://dx.doi.org/10.1109/IGARSS.2010.5652424

Publisher: Institute of Electrical and Electronics Engineers

Persistent URL: http://hdl.handle.net/1721.1/66988

Version: Final published version: final published article, as it appeared in a journal, conference proceedings, or other formally published context

Terms of Use: Article is made available in accordance with the publisher's policy and may be subject to US copyright law. Please refer to the publisher's site for terms of use. 


\title{
DERIVING SOIL MOISTURE WITH THE COMBINED L-BAND RADAR AND RADIOMETER MEASUREMENTS
}

\author{
${ }^{1}$ Jiancheng Shi, ${ }^{2}$ K.S Chen, ${ }^{3}$ L. Tsang, ${ }^{4}$ T. Jackson, ${ }^{5}$ E. Njoku, ${ }^{5}$ J. Van Zyl, ${ }^{6}$ P. O' Neill, ${ }^{7}$ D. Entekhabi, \\ ${ }^{8}$ J. Johnson, and ${ }^{9}$ M. Moghaddam,
}

${ }^{1}$ ICESS, University of California Santa Barbara, CA 93106, USA, shi@icess.ucsb.edu;

${ }^{2}$ Center for Space and Remote Sensing Research, National Central University, Chung-Li, Taiwan, 32001, Republic of China

${ }^{3}$ Department of Electrical Engineering, Box 352500, University of Washington, Seattle, WA 98195-2500, USA

${ }^{4}$ USDA ARS Hydrology and Remote Sensing Lab, USA

${ }^{5}$ Jet Propulsion Laboratory, California Institute of Technology, Pasadena, CA 91109, USA

${ }^{6}$ NASA GSFC Greenbelt, MD 20771, USA

${ }^{7}$ MIT, 15 Vassar St. Cambridge, MA, 02139, USA

${ }^{8}$ Department of Electrical and Computer Engineering, Ohio State University, 2015 Neil Avenue, Columbus, OH 43210, USA

${ }^{9}$ Department of Electrical Engineering and Computer Science, University of Michigan, 1301 Beal Avenue, Ann Arbor, MI 48109-2122, USA

\begin{abstract}
In this study, we develop a combined active/passive technique to estimate surface soil moisture with the focus on the short vegetated surfaces. We first simulated a database for both active and passive signals under SMAP's sensor configurations using the radiative transfer model with a wide range of conditions for surface soil moisture, roughness and vegetation properties that we considered as the random orientated disks and cylinders. Using this database, we developed 1) the techniques to estimate surface backscattering and emission components and 2) the technique to estimate soil moisture with the estimated surface backscattering and emission components. We will demonstrate these techniques with the model simulated data and its validation with the airborne PALS image data from the soil moisture SGP'99 and SMEX'02 experiments.
\end{abstract}

Index Terms - soil moisture, L-band radar and radiometer

\section{INTRODUCTION}

Soil moisture is a key parameter in numerous environmental studies, including hydrology, meteorology, and agriculture. It plays an important role in the interactions between the land surface and the atmosphere, as well as the partitioning of precipitation into runoff and ground water storage. Therefore, the spatial and temporal dynamics of soil moisture are important parameters for various processes in the soil-vegetation-atmosphere- interface. The NASA's Soil Moisture Active and Passive Mission (SMAP) with both Active/Passive L-band instruments will be launched in 2014. The radar operates with $\mathrm{VV}, \mathrm{HH}$, and $\mathrm{HV}$ transmit-receive polarizations, and uses separate transmit frequencies for the $\mathrm{H}(1.26 \mathrm{GHz})$ and $\mathrm{V}(1.29 \mathrm{GHz})$ polarizations. The radiometer operates with $\mathrm{V}, \mathrm{H}$ and $\mathrm{U}$ (third Stokes parameter) polarizations at 1.41 GHz. SMAP will provide a better capability for monitoring global soil moisture and freeze/thaw.

The emission and backscattering models with consideration of the vegetation fraction cover in each pixel resolution can be generally described as:

$$
\begin{aligned}
& \mathrm{T}_{\mathrm{Bp}}^{\mathrm{t}}=\mathrm{T}^{\mathrm{v}} \cdot\left(\mathrm{E}_{\mathrm{p}}^{\mathrm{v}}+\mathrm{E}_{\mathrm{p}}^{\mathrm{sv}}\right)+\mathrm{T}^{\mathrm{s}} \cdot \mathrm{E}_{\mathrm{p}}^{\mathrm{s}} \mathrm{L}_{\mathrm{p}} \quad \text { radiometer } \\
& \sigma_{\mathrm{pq}}^{\mathrm{t}}=\sigma_{\mathrm{pq}}^{\mathrm{v}}+\sigma_{\mathrm{pq}}^{\mathrm{sv}}+\sigma_{\mathrm{pq}}^{\mathrm{s}} \cdot \mathrm{L}_{\mathrm{pq}}^{2} \quad \text { radar }
\end{aligned}
$$

The superscrip $t, v, s$, and $s v$ indicate the total and components from vegetation, soil, and soil-vegetation interaction terms in backscattering or emission, respectively. The subscript $\mathrm{p}$ or pq indicates the polarization status. $T^{v}$ is the temperature of vegetation and $\mathrm{T}^{\mathrm{s}}$ is the soil temperature (Soil Temperature in Wade's data in the simulation). The $\tau$ is the optical thickness. $\mathrm{L}_{\mathrm{p}}=\exp \left(-\tau_{\mathrm{p}} / \cos \theta\right)$ is the attenuation factor or transmittivity of vegetation layer.

Each emission or backscattering terms in (1) can be calculated by the different scattering order in solving 
radiative transfer equations with a given scattering phase function. The shape of scatters (sphere, disk, needle, ellipsoid, short-cylinder, long-cylinder..) and the relation of scatter's size relative to wavelength (small, similar, large) determine what type scattering phase function to be used in calculation, such as Rayleigh, Rayleigh-Gan, physical optics, geometric optics.

However, natural variability and the complexity of the vegetation canopy and surface roughness significantly affect the sensitivity of backscattering and brightness temperature to soil moisture. Backscattering and brightness temperature signals from vegetated areas is a function of water content and its spatial distribution as determined by vegetation structure and underlying surface conditions including surface roughness parameters and dielectric properties. Due to the limited observations from either passive or active measurements alone, an ill condition, the number of measurements and equations is less than the number of unknowns, is expected. It results in the uncertainties in estimation of soil moisture.

It has been realized that both radar and radiometer measurements at L-band are affected by soil moisture, vegetation, surface roughness and temperature. However, how to take each instrument's advantages and avoid its disadvantages to develop a combined active/passive technique to estimate surface soil moisture need to be explored.

In the early study [1], we developed a combined active/passive technique to estimate surface soil moisture with the focus on the short vegetated surfaces. It was found that the small albedo assumption $(\omega=0)$ could result in the significant effects on deriving the ratio of the surface polarization reflectivity, which would greatly impact on the estimation of soil moisture. In that study, we first used the cross-polarization measurements of radar measurements to estimate the vegetation parameter of Vc. With known Vc, the $\omega-\tau$ model for radiometer can be applied without small the albedo assumption. Then, a synthesized technique can be applied to estimate soil moisture from radiometer measurements. The test from the SMEX02 PALS measurements performed reasonable well with the RMSE of $4.7 \%$ for volumetric soil moisture estimation. It was also found the polarization dependence of the vegetation cover has a great impact on the soil moisture estimation and needs to be considered in future study.

In this study, we evaluate whether we can improve the soil moisture estimation accuracy by developing a inversion method without the independent polarization assumption on vegetation effects. We first simulated a database for both active and passive signals under SMAP's sensor configurations using the radiative transfer model with a wide range of conditions for surface soil moisture, roughness and vegetation properties with the different shapes of disks, needles, and cylinders. Using this database, we evaluated the relationships between each backscattering and emission components. Through analyses of these relationships, we developed a technique to estimate surface soil moisture.

\section{RELATIONSHIP BETWEEN RADAR AND RADIOMETER MEASUREMENTS}

For simplicity, the $\omega-\tau$ model for radiometer and Ulaby's semi-empirical model [2] for radar will be used to demonstrate the relationship between radar backscattering coefficients and emissivity. We re-write (1) for passive emissivity as

$$
\begin{aligned}
\mathrm{E}_{\mathrm{p}}^{\mathrm{t}} & =1-\omega \cdot\left(1-\mathrm{L}_{\mathrm{p}}\right)-\mathrm{R}_{\mathrm{p}}^{\mathrm{e}} \cdot \mathrm{L}_{\mathrm{p}} \cdot\left\lfloor 1-\mathrm{E}_{\mathrm{p}}^{\mathrm{v}}\right\rfloor \\
& =1-\mathrm{V}_{\mathrm{c}}-\mathrm{R}_{\mathrm{p}}^{\mathrm{e}} \cdot \mathrm{V}_{\mathrm{e}}
\end{aligned}
$$

Where $\mathrm{V}_{\mathrm{c}}=\omega \cdot\left(1-\mathrm{L}_{\mathrm{p}}\right)$ is the vegetation correction factor. $\mathrm{V}_{\mathrm{e}}=\mathrm{L}_{\mathrm{p}} \cdot\left(1-\mathrm{E}_{\mathrm{p}}^{\mathrm{v}}\right)$ is the vegetation attenuation factor. For radar backscattering

$$
\begin{aligned}
\sigma_{\mathrm{pq}}^{\mathrm{v}}= & 0.742 \cdot \omega \cdot \cos \theta \cdot\left(1+0.536 \cdot \omega \tau-0.237 \cdot(\omega \tau)^{2}\right) \\
& \cdot[1-\exp (-2.119 \cdot \tau \cdot \sec \theta)] \\
\sigma_{\mathrm{pq}}^{\mathrm{sv}}= & 1.924 \cdot \omega \cdot \cos \theta \cdot\left(1+0.924 \cdot \omega \cdot \tau+0.398 \cdot(\omega \tau)^{2}\right) \\
& \cdot[1-\exp (-1.925 \tau \sec \theta)] \\
& \cdot \exp \left(-1.372 \tau^{1.12} \sec \theta\right) \cdot \exp \left[-0.84(\mathrm{ks})^{2} \cos \theta\right] \cdot \mathrm{r}_{\mathrm{p}}
\end{aligned}
$$

Where $\mathrm{ks}$ is the surface roughness parameter: the normalized surface rms height. For canopy structure is dominated by vertically oriented cylinders (stalks or stems), the interaction component in (1) was given by [3] as

$\sigma_{\mathrm{hh}}^{\mathrm{sv}}=2 \cdot \exp (-2 \cdot \tau \cdot \sec \theta) \cdot \exp \left(-(2 \cdot \mathrm{ks} \cdot \cos \theta)^{2}\right) \cdot \mathrm{r}_{\mathrm{h}} \cdot\left|\mathrm{R}_{\mathrm{st}}\right|^{2}$

Where $\left|R_{s t}\right|^{2}$ is the effective reflectivity of the stalk components of the canopy, which varies with vegetation water content. The total contribution of a canopy in backscattering and emission can be, then, added together from each constituent with the modification of the optical thickness or the attenuation factor (sum of all constituents) as shown in [2]. In any case above, we can write the interaction term as a function:

$$
\sigma_{\mathrm{pp}}^{\mathrm{sv}}=\mathrm{Cf}_{\mathrm{pp}}(\text { roughness, veg }) \cdot \mathrm{r}_{\mathrm{p}}
$$

For radar surface backscattering components at L-band, we can write: 


$$
\sigma_{\mathrm{pp}}^{\mathrm{s}}=\mathrm{Sr}_{\mathrm{pp}}(\text { roughness }) \cdot\left|\alpha_{\mathrm{pp}}\right|^{2}
$$

Where $\left|\alpha_{\mathrm{pp}}\right|^{2}$ is the polarization magnitude, which is a function of soil surface dielectric constant and incidence angle. Figure 1 show the relationships between the dielectric functions $\left(\left|\alpha_{\mathrm{pp}}\right|^{2}\right.$ and $\left.\mathrm{rp}\right)$ in backscattering and emission models for radar hh vs emission $\mathrm{h}$ at left and radar vv vs. emission $\mathrm{v}$ in middle, and $\mathrm{rv} v \mathrm{vs}$. rh in emission, respectively. For the same polarization status as shown in Figure 1 (left and middle), they can be seen:

$$
\mathrm{c} \cdot\left|\alpha_{\mathrm{pp}}\right|^{2} \approx \mathrm{r}_{\mathrm{p}}
$$

The scale $c$ differs for different polarization. For $\mathrm{hh} / \mathrm{h}$ polarization, the scale $\mathrm{c}$ is very close to unit. Due to the frequency dependence of water part of dielectric constant, there is a slight difference in $\left|\alpha_{\mathrm{hh}}\right|^{2}$ and rh at a given soil moisture because of the central frequency difference in SMAP's radar $(1.26 \mathrm{GHz})$ and radiometer $(1.41 \mathrm{GHz})$. On the other hand, $\left|\alpha_{\mathrm{vV}}\right|^{2}$ and $\mathrm{rv}$ are scaled differently. Furthermore, when cross the polarizations, $\left|\alpha_{\mathrm{vv}}\right|^{2}$ and $\left|\alpha_{\mathrm{hh}}\right|^{2}$ or $\mathrm{rv}$ and rh have to be described as a non-linear functions.
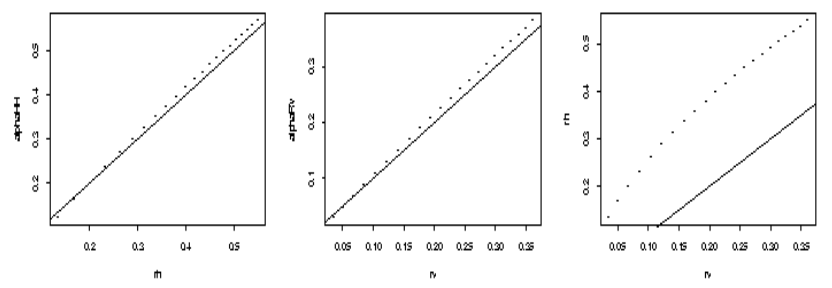

Figure 1. The relationships between the dielectric functions $\left(\left|\alpha_{\mathrm{pp}}\right|^{2}\right.$ and $\mathrm{rp}$ ) in backscattering and emission models for radar hh vs emission $\mathrm{h}$ at left and radar vv vs. emission $\mathrm{v}$ in middle, and $\mathrm{rv} v \mathrm{vs}$. rh on right, respectively.

The relationship between radar and radiometer measurements in a same polarization, therefore, can be written as:

$$
\mathrm{r}_{\mathrm{p}} \approx\left\{\begin{array}{c}
\left(1-\mathrm{V}_{\mathrm{c}}-\mathrm{E}_{\mathrm{p}}^{\mathrm{t}}\right) /\left(\exp (-\mathrm{h}) \cdot \mathrm{V}_{\mathrm{e}}\right) \\
\mathrm{c} \cdot\left(\sigma_{\mathrm{pp}}^{\mathrm{t}}-\sigma_{\mathrm{pp}}^{\mathrm{v}}\right) /\left(\mathrm{Cf} \mathrm{fp}_{\mathrm{pp}}(\text { roughness veg })+\mathrm{Sr}_{\mathrm{pp}} \cdot \mathrm{L}_{\mathrm{pp}}^{2}\right)
\end{array}\right.
$$

By re-ranging (9), we obtain the relationship between radar backscattering and emission signals at the same footprint scale.
$\mathrm{E}_{\mathrm{p}}^{\mathrm{t}}=1-\mathrm{V}_{\mathrm{c}}-\mathrm{c} \cdot \frac{\exp (-\mathrm{h}) \cdot \mathrm{V}_{\mathrm{e}}}{\mathrm{Cf}_{\mathrm{pp}}(\text { roughness veg })+\mathrm{Sr}_{\mathrm{pp}} \cdot \mathrm{L}_{\mathrm{pp}}^{2}} \cdot\left(\sigma_{\mathrm{pp}}^{\mathrm{t}}-\sigma_{\mathrm{pp}}^{\mathrm{v}}\right)$

From (10), we can see that backscattering and emission signals for the same polarization status can be written as a linear function. The intercept and slope of this function depend on both surface roughness and vegetation properties. In addition, it is also expected that the relationship between radar and emission measurements for across polarizations is to be non-linear as shown in Figure 1 (right).

\section{INVERSION TECHNIQUES}

It has been realized that the different radar polarization measurements has the different sensitivities to the different surface properties. Especially, the radar cross-polarization measurements are very sensitive to the vegetation information since the surface backscattering does not generate significant cross-polarization signal. As shown in [4], the direct volume backscattering component of the copolarizations in (1) for the random orientated short cylinders can be directly estimated from the cross-polarization signals. That is

$$
\sigma_{\mathrm{pp}}^{\mathrm{v}}=3 \cdot \sigma_{\mathrm{vh}}^{\mathrm{t}}
$$

As shown in the study [1], Vc and $\sigma_{\mathrm{pp}}^{\mathrm{v}}$ in (1), (2) and (3) are highly correlated. Their relationship can be well characterized as

$$
\log \left(\mathrm{V}_{\mathrm{c}}\right)=\mathrm{a}+\mathrm{b} \cdot \log \left(\sigma_{\mathrm{pp}}^{\mathrm{v}}\right)
$$

Therefore, we can estimated the direct volume scattering term $^{\sigma_{\mathrm{pp}}^{\mathrm{V}}}$ in radar measurements and $\mathrm{Vc}$ term in emission measurements from the radar cross polarization measurements.

From (2), by combining the surface roughness and vegetation terms together, we can obtain

$$
\mathrm{r}_{\mathrm{p}} \cdot \mathrm{C}_{\mathrm{p}}=\mathrm{R}_{\mathrm{p}}^{\mathrm{e}} \cdot \mathrm{V}_{\mathrm{e}}=1-\mathrm{V}_{\mathrm{c}}-\mathrm{E}_{\mathrm{p}}^{\mathrm{t}}
$$

Where $\mathrm{rp}$ is the flat surface reflectivity for polarization $p . \mathrm{Cp}$ is the combined surface roughness and vegetation factor for the polarization $p$. Similarly, we can obtain the radar measurements from (1), (6), and (7) as:

$$
\sigma_{\mathrm{pp}}^{\mathrm{t}}-\sigma_{\mathrm{pp}}^{\mathrm{v}}=\left|\alpha_{\mathrm{pp}}\right|^{2} \cdot\left(\mathrm{Cf}_{\mathrm{pp}}+\mathrm{Sr}_{\mathrm{pp}} \cdot \mathrm{L}_{\mathrm{pp}}^{2}\right)=\left|\alpha_{\mathrm{pp}}\right|^{2} \cdot \mathrm{C}_{\mathrm{pp}}
$$

Furthermore, we can use the relationship between $\left|\alpha_{\mathrm{pp}}\right|^{2}$ and $\mathrm{r}_{\mathrm{q}}$ to derive a general form 


$$
\left|\alpha_{\mathrm{pp}}\right|^{2}=\mathrm{A}_{\mathrm{ppq}} \cdot \mathrm{r}_{\mathrm{q}} \mathrm{B}_{\mathrm{ppq}}
$$

By replacing two radiometer measurements from (13) and two radar measurements from (14) into (15), we can obtain six different ratio combinations of $\mathrm{Ch}, \mathrm{C}_{\mathrm{v}}, \mathrm{Chh}$, and $\mathrm{C}_{\mathrm{vv}}$. These ratio combinations are independent of surface dielectric properties and only depend on vegetation on roughness properties. All parameters of A and B in (15) can be determined from the regression and depend on the incidence angle and the pair of the polarizations and measurements. They can be estimated by the numerical technique. That is to use the six different ratio combinations to solve four unknowns $\mathrm{Ch}, \mathrm{Cv}, \mathrm{Chh}$, and $\mathrm{Cvv}$. Therefore, soil moisture can be estimated.

\section{INVERSION WITH PALS MEASUREMENTS}

PALS [5] is a non-scanning real aperture combined microwave radiometer and radar, operating at 1.41 and 2.69 $\mathrm{GHz}$ (radiometer) and 1.26 and $3.15 \mathrm{GHz}$ (radar) with multiple polarizations. The instrument was designed for high accuracy measurements of ocean salinity and soil moisture. The radiometer operates at $\mathrm{V}$ (vertical) and $\mathrm{H}$ (horizontal) polarizations, while the radar operates at VV, $\mathrm{HH}$, and VH polarizations. For SGP' 99 and SMEX'02 the incidence angles were fixed at $38^{\circ}$ and $45^{\circ}$, respectively. The instrument thus samples a single footprint track along the flight path. At a nominal flight altitude of $1 \mathrm{~km}$ and incidence angles the instantaneous $3-\mathrm{dB}$ footprints at the surface are approximately $330 \times 470 \mathrm{~m}$.

Figure 2 shows the comparison of the PALS estimated soil moisture with a total of 257 ground measurements in SGP'99 and SMEX'02 experiments. The results are very encourage with overall RMSE of $3.8 \%$ for the volumetric soil moisture. The right plot in Figure 2 is the histogram of the absolute error. It indicates that $85 \%$ of them less than $4 \%$ error, only $15 \%$ of them are greater than $4 \%$ error.
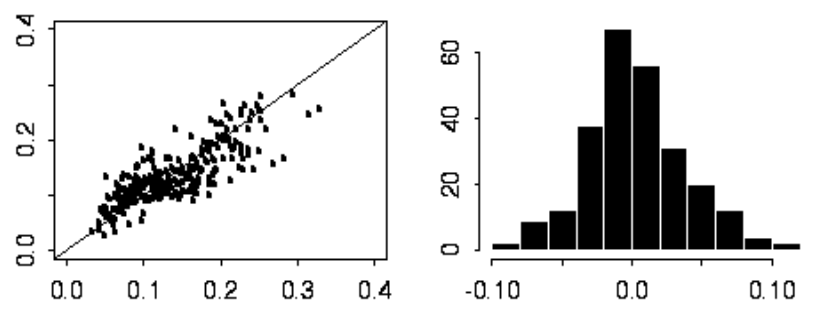

Figure 2. Comparison of the estimated soil moisture with PALS instruments with the total 257 ground measurements in SGP'99 and SMEX'02 experiments.

\section{SUMMARY}

We studied a technique to estimate soil moisture with the combined passive/active measurements

1. Relationship between radar and radiometer measurements can be decribed as a linear function;

2. Radar Cross-Pol measurement can be used to estimate the volume scattering component in CoPol measurements. It also provides Vc estimation to reduce the error due to small albedo assumption in representing radiometer measurements. It is important in multi-channel approach.

3. Demonstrated a technique to estimate soil moisture.

4. Test with PALS measurements from SGP'99 and SMEX'02 shows a significant improvement in soil moisture estimation over a passive technique.

\section{REFERENCES}

[1] Shi, J., K. S. Chen, Y. Kim, J. J. Van Zyl, E. Njoku, T. Jackson and P.O'Neill, "Estimation of soil moisture with the combined L-band Radar and Radiometer Measurements", Proceedings of IGRASS'05, IEEE , No. 05CH37663C, July 25-29, 2005.

[2] Ulaby, F. T., R. K. Moore and A. K. Fung, 1986, Microwave Remote Sensing: Active and Passive, 3, Volume Scattering and Emission Theory, Advanced Systems and Applications, Reading, MA, Addison-Wesley.

[3] Dobson, C.M. and Ulaby, F.T., 1986a, "Preliminary evaluation of the SIR-B response to soil moisture, surface roughness, and crop canopy cover", IEEE Trans. Geosci. and Remote Sens., GE24(4):517-526.

[4] Freeman, A. and S. L. Durden, "A three-component scattering model for polarimetric SAR data", IEEE Trans. Geosci. and Remote Sens., 36(3):963-973, May 1998.

[5] Wilson, W. J., S. H. Yueh, S. J. Dinardo, S. Chazanoff, F. K. Li, and Y. Rahmat-Samii, "Passive Active L- and S-band (PALS) microwave sensor for ocean salinity and soil moisture measurements," IEEE Trans. Geosci. Rem. Sens., vol. 39, pp. 1039-1048, 2001. 